\title{
Para além da racionalidade - as complexidades inerentes à relação economia, política e mídia*
}

Karina Gomes de Assis**

Resumo

0 presente artigo tem por interesse a elucidação das complexidades inerentes ao contexto da economia e de sua interseção com os mundos político e midiático. Destaca contribuições sociológicas, mais especificamente da Sociologia Econômica, para desconstruir racionalidades e posicionamentos objetivos que, por meio da mídia, repercutem na cena política. Demonstra as tensões sociais e os movimentos de grupos por trás das prescrições e debates econômicos, chamando a atenção para o fato de que dispositivos, leis e normas originários da Economia não dependem única e exclusivamente dos modelos racionais produzidos pelo homo economicus, ao contrário, são construções advindas de embates culturais entre visões de mundo e seus grupos defensores. Para tal, se atém a um momento específico da cena brasileira qual seja a disputa em torno da transição entre os governos FHC e Lula, entre os anos de 2002 e 2003, e as tentativas de atrelar ao novo governo a possibilidade de uma crise econômica em decorrência de seus posicionamentos políticos.

Palavras-chave: Interseção econômica, mídia e política, transição entre governos.

* 0 artigo aqui apresentado é resultado de pesquisa realizada em tese de doutoramento defendida em 2016 no Programa de Pós-graduação em Ciência Política da Universidade Federal de São Carlos (UFSCar), de título "Verdades Econômicas e Verdades Políticas - 0 Sistema Financeiro em Debate".

** Doutora em Ciência Política com doutorado sanduíche na École des Hautes Études em Sciences Sociales e pesquisadora do Núcleo de Estudos em Sociologia Econômica e das Finanças - NESEFi/UFSCar. E-mail: karinag.assis@gmail.com. 


\section{Beyond rationality - the complexities inherent in the relationship among economics, politics and the media}

Abstract

The present article intends to debate the elucidation of the complexities inherent in the context of the economy and its intersection with the political and media fields. It emphasizes sociological contributions specifically from Economic Sociology, to deconstruct rationalities and objective positions that reverberate in the political scene through the media. It demonstrates the social tensions and group movements behind economic prescriptions and debates, drawing attention to the fact that devices, laws and norms originating in the Economy do not depend solely on the rational models produced by the homo economicus, but rather are constructions coming from cultural clashes between worldviews and their advocacy groups. To this end, this article drawns on the specific moment in the Brazilian political scene concerning the dispute over the transition between the FHC and Lula governments, between 2002 and 2003, and the attempts to connect the new government with the possibility of an economic crisis due to its political position.

Keywords: Economy, media and political intersection, transition between governments

\section{Introdução}

Acontecimentos recentes na política brasileira ilustram com veemência a relação entre economia e política e o papel da mídia na divulgação de olhares e pontos de vista favoráveis a determinado grupo e na omissão de alguns outros conforme personagens e interesses envolvidos. Dos fatos que encadearam o impeachment 
da presidenta Dilma Rousseff em 2016, passando pelas inúmeras delações da investigação Lava Jato ${ }^{1}$, até às últimas denúncias feitas por Joesley Batista, empresário da $\mathrm{JBS}^{2}$ - podemos a grosso modo concluir que, sem adentrarmos no mérito de cada uma das situações, para além dos escândalos que repercutem, nelas são evidenciadas questões morais que circundam a interseção desses três mundos - que, embora próximos e em diálogo, deveriam manter-se numa relação independente em contribuição à manutenção da atual democracia.

As denúncias de 18 de maio de 2017, que acusaram o então presidente Michel Temer de dar informações privilegiadas sobre a queda da taxa de juros a Joesley Batista ${ }^{3}$, verdade ou não, enveredam o olhar para essa interseção que, a todo momento, é negada nos discursos próprios de cada um desses mundos e serve como exemplo do quão constante são as situações em que esta relação é questionada e, ao final, neutralizada pelos argumentos do bem comum, da objetividade e da racionalida-

1 Investigação sobre corrupção e lavagem de dinheiro operada pela Polícia Federal Brasileira, que vem despertando críticas pelo seu posicionamento e conduta na condução das investigações.

2 A JBS S.A. é uma empresa brasileira de amplitude internacional que atua no mercado mundial de processamento de carnes bovina, suína, ovina e de frango e também no processamento de couro.

3 Sobre os acontecimentos referentes à JBS ver: Temer sugere corte de juros do Banco Central Joesley, segundo delação. Folha.com, São Paulo, 18 mai. 2017. Mercado. Disponível em: <http://www1.folha.uol.com.br/mercado/2017/05/1885114-temer-antecipou-corte-de-juros-do-bc-a-joesley-segundo-delacao.shtml>. Acesso em: 19 mai. 2017; 0 áudio entre Michel Temer e Joesley Batista em quatro pontos. Carta Capital, São Paulo, 18 mai. Política. Disponível em: https://www.cartacapital.com.br/politica/o-audio-entre-michel-temer-e-joesley-batista-em-quatro-pontos>. Acesso em: 19 mai. 2017; Temer vazou a Joesley informação de que juros cairiam 1 ponto no Copom de abril. Época Negócios Online, São Paulo, 19 mai. 2017. Disponível em: <http://epocanegocios.globo.com/Brasil/noticia/2017/05/epoca-negocios-temer-vazou-a-joesley-informacao-de-que-juros-cairiam-1-ponto-no-copom-de-abril.html>. Acesso em: 19 mai. 2017; Temer antecipou corte da Selic a Joesley Batista. Infomoney, São Paulo, 18 mai. 2017. Mercados/Política. Disponível em: <http://www.infomoney.com.br/mercados/politica/noticia/6506965/temer-antecipou-corte-selic-joesley-batista>. Acesso em: 19 mai. 2017. 
de, que pautam cada um dos mundos de modo geral. Ao contrário do que se deseja fazer imaginar, essas relações não são recentes, tampouco pontuais, são situações que por serem veladas passam despercebidas ao olhar cotidiano diante do discurso imperioso e, às vezes, moralista de cada um dos campos que aqui tratamos.

Nessa toada, o presente artigo intenta, a partir de um cenário específico da realidade brasileira, debater a repercussão da convergência entre esses três campos diante da possibilidade de alteração nos rumos político-econômicos e também sociais do país em decorrência da possibilidade de transição entre governos dotados de visões de mundos distintas.

Refere-se aos anos de 2002 e 2003 quando se configura a disputa política em que se almeja a presidência da República, disputa liderada por José Serra (PSDB) e Luís Inácio Lula da Silva (PT), ao mesmo tempo em que se concretiza o embate cultural entre concepções distintas sobre a condução da política brasileira e principalmente da política econômica. Nessa ocasião é interessante notar quanto o debate e o embate ganham planos mais amplos que o espaço político em si, seu teor e a definição do próximo presidente parecem se delinear quase exclusivamente no plano econômico-financeiro, ganhando dimensões significativas com a divulgação de previsões catastróficas na mídia.

Depois das diversas tentativas de chegar à presidência, a candidatura de Lula ao final de 2001 desponta como promissora para o cenário que se criara a partir das sucessivas crises enfrentadas principalmente a partir do segundo mandato de Fernando Henrique Cardoso (FHC). Este, passados oito anos de governo, trazia como legado incertezas decorrentes de uma recente crise energética, da alta nas taxas de desemprego e de críticas relacionadas às privatizações, que incidiram negativamente sobre as alianças políticas firmadas nos anos anteriores (Couto e Abrucio, 2003) e 
repercutiram na candidatura de seu possível sucessor pelo PSDB, José Serra ${ }^{4}$.

É ali travada uma disputa entre o perfil do sindicalista agressivo, alimentado constantemente pela mídia através de matérias sobre sua trajetória ${ }^{5}$ e suas críticas sobre a conduta econômica brasileira desde as primeiras candidaturas, e o candidato da situação que, embora fosse a esperança do partido diante das críticas ao governo FHC, tentava se apresentar como uma alternativa distinta da trajetória governista. Sendo os dois candidatos mais expressivos dessa disputa eleitoral, trataremos aqui das circunstâncias gerais que a cinge.

Faz-se relevante notar as pautas e, sobretudo, o domínio sobre a definição de um bom presidente ou candidato à presidência que são exaustivamente debatidos na mídia. Nesse período, temas econômicos foram discutidos à luz de questões mais amplas que versavam, de modo geral, sobre o ordenamento da sociedade brasileira, corroborando para a conclusão de que o momento diz muito mais respeito à ordem cultural a ser legitimada do que à uma disputa política ou econômica simplesmente.

A insistência sobre a previsibilidade de caos, sobretudo econômico, em decorrência da possibilidade de vitória de Lula, aparece alicerçada em sequências de gráficos, escalas de queda de classificação de risco, queda do dólar, etc., revestida assim do

4 Na disputa interna ao partido (PSDB) José Serra obteve vitória frente a Tasso Jereissati por ser considerado como representativo daquilo que 'faltou' ao governo FHC. Pertencente à ala mais desenvolvimentista do partido, dialogava com as críticas que recaiam sobre o legado do governo de Fernando Henrique Cardoso e se tornaria uma alternativa menos contrastante com o seu grande adversário Lula.

5 A imagem de Lula, remodelada para as eleições de 2002, é a todo momento confrontada com suas posições políticas e trajetória sindical na tentativa de atrelar à sua mudança o puro interesse pela obtenção do poder. Segundo seus críticos, Lula aderira a essa mudança com o intuito de 'enganar' a população brasileira sobre seus posicionamentos anteriormente mais agressivos. A transformação do Sapo Barbudo em Lula Paz e Amor é assunto na mídia durante um longo período. 
teor racional próprio da econometria que empodera o olhar econômico - trazendo-a para o plano objetivo e 'isento', ao menos para o senso comum, de interesses obscuros; aparece também na sequência de matérias sobre o assunto, ou, mais precisamente, na insistência do tema como pauta, seguido de avaliações de consultorias de riscos, economistas críticos ao Partido Trabalhista e Lula, sondagens de opinião, que através do apelo à objetividade jornalística (presente no discurso de defesa do atuar jornalístico) ganha o status de exclusivamente informativo, embora priorizando fortemente um dos lados. 0 caos é retratado e personificado também a partir do espaço político por meio de pronunciamentos de deputados, senadores em diferentes situações reiterando a previsibilidade do caos econômico respaldado no critério do bem comum, dever da política como um todo.

Posicionamentos de atores e grupos de diferentes campos atuam em consonância no esforço de cristalizar um olhar que embora não tenha correspondido àquele triunfante, dada a vitória de Lula naquela eleição, salienta a interseção desses três espaços e, mais, revela como esta relação produz possibilidades e busca definir o caminho possível - é assim, através das tentativas de domínio das estruturas cognitivas que se baliza o provável, o pensável. Busca-se, portanto, neste artigo, dar ênfase aos movimentos que tal confluência produz e que intentam estabelecer critérios, caminhos, possibilidades, limitando olhares e direcionando escolhas (Lakoff, 1996; Lakoff; Johnson, 1980). Para refletir sobre as disputas culturais (Grün, 2004; 2013) que balizam o cenário político-econômico, a partir da interseção entre economia, política e mídia no período da disputa eleitoral em questão, foram analisadas reportagens dos jornais Folha de S. Paulo e 0 Globo entre os meses de janeiro e setembro de $2002^{6}$. 
Como resultado dessa pesquisa, são realizadas neste artigo três discussões: na primeira, a partir do tópico "Economia, Política e Mídia", características e especificidades de cada um destes mundos e os seus pontos de confluência são apresentados demonstrando o movimento de ressignificação das ações econômicas a partir do orquestramento de seus interesses. Essa dinâmica permite que verdades sejam construídas e disseminadas a partir das medições e prescrições de determinados agentes, como os think tanks e financistas, a partir de métodos econométricos - apresentado no segundo tópico "Previsões, Medições e Prescrições". Por fim, em "Concretizando Olhares, Produzindo Caminhos" são discutidos os desdobramentos dos conflitos que envolvem esses três espaços e como os dispositivos econômicos são utilizados para legitimar e estabelecer uma concepção de 'futuro' para o país naquele momento.

\section{Economia, Política e M ídia}

O jogo que se forma, complexo e diferente da lógica que cada um dos espaços tenta imputar sobre o imaginário social, ludibria os olhares e ressignifica as ações que advém deste orquestramento de interesses comuns, desviando a atenção e fazendo-se crer que dizem respeito única e exclusivamente a um espaço orientado por um ethos característico. Entretanto, percebe-se que a trama não diz respeito exclusivamente à interseção objetiva entre política, mídia e economia, demonstra-se muito mais complexa que isto: direcionam essas condutas e relações, atores e grupos que nestes campos se fazem atuantes, os quais são responsáveis pela construção e reconstrução dos significados atribuídos a esta relação a partir das disputas que travam em seus respectivos espaços - são eles economistas, jornalistas e políticos.

Desse modo, se pode afirmar que a estrutura do campo e suas disputas, bem como os habitus e os capitais dos agentes ali envolvidos, refletem na estruturação de um cenário oportuno para 
a formulação e aceitação do que é criado como possibilidade (Bourdieu, 1992), o que leva a crer que reconhecer as especificidades de cada um desses três campos permite depreender a formação da trama que ambiciona persuadir as decisões do pleito.

Dotada da excelência numérica, que lhe aproxima da objetividade, a economia enquanto ciência e prática tende a ser interpretada como distanciada das interferências diversas que existem no mundo social. Como bem demonstra Lebaron (2000) sua ligação com o cálculo lhe oferece o status de 'neutra' embora seja uma ciência muito mais social do que exata, suscetível às condições sociais em que é aplicada. Nesse sentido, oferece a racionalidade científica àqueles que dela fazem uso (Assis, 2016) e o poder de controlar a narrativa na medida em que seduz pela aplicabilidade do seu quadro de análise a todo e qualquer comportamento humano por meio da abstração e simplificação da realidade, pela produção de previsões e pela elegância de suas deduções (Hirsch, 2003).

Assim, do campo econômico sobressaem a racionalidade e o tecnicismo, parâmetros que induzem a crer no distanciamento dos interesses políticos durante as avaliações econômicas, dado que os números, sendo objetivos, 'não mentem'. Como fruto do saber científico moderno, ao qual estão relacionados a objetividade e o conhecimento impessoal, as análises econômicas e principalmente as que fazem uso da econometria livram-se das suspeitas de interferência ganhando ao mesmo tempo prestígio e autoridade (Porter, 1995; Bourdieu, 2006), embora estejam inclinadas a simplificar a realidade.

Ganha muitas vezes destaque como disciplina moralmente correta através da prescrição de condutas direcionadas para o controle dos gastos públicos, obtendo espaço em sociedades nas quais a corrupção aparece de forma significativa. Essa reputação concede aos economistas força para que se tornem porta-vozes de 'verdades' - repercutem na influência de governos, empresá- 
rios e população em geral por meio de noções e dispositivos, a exemplo da governança estatal, empresarial e da maximização do bem estar social. Permite também aproximação com a imprensa, na medida em que o ethos profissional do jornalismo é pautado nos princípios democráticos e na conformidade/informação dos fatos combinando facilmente com a dedução, a previsão e a prescrição, características do interpretar econômico (Puliti, 2009).

Tal proximidade favorece a economia como "enquadramento mais geral de análise dos fenômenos da sociedade" (Assis, 2016, p. 225) permitindo o espraiamento de concepções econômicas, além da sua disseminação a partir de chaves interpretativas mais simples em decorrência da atuação dos think tanks - situação que conduz a formação de uma lente interpretativa da realidade social, considerando-se dentro desse espaço escolas de pensamento específicas detentoras de maior legitimidade no campo, conhecidas como mainstream, que resultam do próprio espaço de lutas no interior deste campo.

As lutas de classificação no interior do campo econômico delineiam as características do 'verdadeiro economista' a partir da determinação de atributos legítimos, das técnicas que se associam a esta noção e de suas qualificações, que dizem respeito às distintas formas de autoridade, de prestígio e também de poder social. Essas lutas repercutem diretamente nas instâncias de formação dos economistas, bem como no contato entre a profissão e o mundo social, a exemplo de suas publicações, participações em colóquios e de sua inserção na mídia.

Apresenta-se como um campo cuja estrutura é fundamental para a formatação do debate aqui apresentado considerando que o resultado da luta de forças em seu interior repercute diretamente na legitimação de ideias na sociedade e determina a presença no campo do poder. Ao demonstrar sua influência em diversos espaços comprova-se capaz de relativizar a autonomia 
de determinados campos (Bourdieu, 2006). Desse modo, o campo econômico se apresenta como fundamental para o fortalecimento e legitimidade de determinadas concepções de sociedade.

A relação entre os agentes do campo econômico e aqueles do campo político é que produz a interseção entre estes dois mundos, podendo ocorrer dentre outras formas, pelo financiamento de campanhas e projetos políticos.

No campo político, que não se confunde com o Estado, a notoriedade de seus agentes reside na sua capacidade de se fazer ver e de se fazer crer (Mauger, 2013), em um jogo no qual a imposição legítima dos princípios de visão e de divisão do mundo social é que atribui significado ao espaço. Essa necessidade, de ser conhecido e reconhecido, também aproxima os campos político e midiático, extrapolando a relação direta político-eleitores e permitindo ressaltar demais interesses na ação política normalmente camuflados nos discursos que enfatizam o compromisso com o eleitorado e com o bem comum. Nesta última, é interessante perceber seu efeito de censura que limita o pensável politicamente, pois, ao demarcar a problemática política, delimita o universo do discurso político (Bourdieu, 2012).

Dependente do eleitorado, esse campo não pode se autonomizar por completo uma vez que atua em nome de um conjunto maior de interesses, qual seja o da população - que tem influência no campo a partir do voto. Consequentemente, está fadado às influências da vontade popular embora seus agentes encontrem recursos para contornar tal situação, parte deles através de sua relação com os meios de comunicação. Diante de tal fato, torna-se relevante notar como jornalistas e especialistas em sondagens, por exemplo, transformam-se em agentes do campo político produzindo enquadramentos e propalando opiniões que favorecem determinados atores, direcionando a opinião pública também a partir do agenda setting - o modo de apresentação dos conteúdos bem como sua formatação que influenciam a lei- 
tura do cenário apresentado e sua compreensão (Porto, 2002; Cappella e Jamieson, 2007; Scheufele, 2000).

No universo midiático, por sua vez, sobretudo o jornalismo impresso e televisivo que a este trabalho interessa, é notória a influência do campo econômico. Se de um lado o índice de audiência molda o critério de escolha da programação revelando o interesse pela dramatização e o excessivo número de casos sensacionalistas (Boltanski, 1993; Bourdieu, 1997), por outro, a influência e pressão de anunciantes, de grandes grupos industriais e financistas, colocam o jornalismo impresso diante da perda de sua independência editorial (Champagne, 1995; Duval, 2004).

Do mesmo modo, como os outros dois campos, é pautado por lutas internas em que o interesse reside na distinção e no reconhecimento. Dessa forma, sempre são encontrados posicionamentos que disputam entre si a melhor e mais legítima definição sobre o papel do jornalismo e do perfil legítimo do jornalista. De caráter fortemente político e intimamente ligado ao campo da produção trata-se de uma instância de circulação que na maioria das vezes serve a interesses específicos, a grupos de poder, sendo ainda capaz de interferir na cena política e social reforçando ou evocando a representatividade de um ponto de vista (Assis, 2016).

Isso posto, é pertinente afirmar que o debate em questão reflete as disputas pelo campo do poder na medida em que tais campos encontram-se envolvidos numa luta simbólica para imporem uma definição sobre o mundo social condizente com seus interesses (Bourdieu, 1998). São as disputas no interior do campo político que delimitam as forças suscetíveis de engajamento nessa luta quando este se define como espaço de relações de força entre agentes dominantes em seus diferentes campos.

Das características de cada campo (econômico, jornalístico e político) faz-se interessante ressaltar o processo simbólico de 
legitimação da atuação dos atores e as justificativas que lançam para amenizar seus posicionamentos. Estes, se revestem de um ideário superior relacionado à profissão ou à prática em questão para afastarem-se das acusações de beneficiamento individual, compreendido como nocivo para o desenvolvimento de políticas de interesse da sociedade.

Nesse sentido, é nítido, no debate aqui apresentado, o esforço em fazer prevalecer nesses campos, respectivamente, a racionalidade, a objetividade e o bem comum como fundamentais nas tomadas de posição, tanto na determinação do que é certo ou errado, e quais os caminhos para o futuro econômico do país, como para a escolha do futuro presidente brasileiro. Desse modo, tendem a corroborar com um modelo de modernização que vai ao encontro de a uma visão de mundo peculiar aos poderes econômicos privados (Lebaron, 2000; Duval, 2000). Essa visão racional legitimada para a análise da conjuntura políticoeconômica brasileira dissemina a ideia de que não há outra alternativa melhor que não seja esta disseminada e já encaminhada no governo que chega ao fim em 2002 (FHC), ditando ao tom do debate o caráter TINA (there is no alternative) ressaltado por Paulani (2008).

No período, percebe-se um forte movimento da mídia na tentativa de legitimar uma única visão de mundo, ao polarizar o certo e o errado, considera a existência de apenas uma conduta econômica legítima - aquela hegemônica, ortodoxa. Fato observado em Faria (1994), em que é demonstrado o papel da mídia no endosso dos programas de privatizações iniciados na década de 1990, sendo possível observar a continuidade desta ênfase na década seguinte (Assis, 2016). Na grande parte das vezes é ressaltada a perspectiva de ajuste das contas públicas a partir da redução do tamanho do Estado, em detrimento dos pontos críticos de sua aplicação - raramente há apresentação de um contraponto à visão dominante e favorável ao caminho incentivado. 
A mídia se torna um espaço de formulação e disseminação de crenças e consensos, divulgando e dando força ao discurso econômico (Ortiz, 2006), tanto pela noticiabilidade (Kovack e Rosenstiel, 2004) como pela dependência de recursos econômicos de grandes grupos financeiros patrocinadores (Champagne, 1995; Duval, 2000). Ao dar destaque a temas específicos partindo de um ponto de vista e não outro, os jornalistas atuam como gatekeepers direcionando a opinião pública (Assis, 2016).

Considerando a influência que possui sobre a forma como o mundo é interpretado, o jornalismo se revela peça fundamental para o reverenciamento de uma visão de mundo, torna-se necessário ser legitimado pela imprensa para obter repercussão. Contudo, o discurso formado pelo ethos profissional que cinge a profissão jornalística se desenvolve de maneira contrária a essa que aqui é demonstrada, evidenciando o jogo de forças a que estão submetidos os agentes em disputa no campo e sua vulnerabilidade diante da pouca autonomia do campo midiático em relação ao campo econômico (Champagne, 1995).

Questão similar também aparece no campo político, e situações parecidas podem ser encontradas a partir da sua relação com os outros dois campos. Como visto, a inserção dos interesses econômicos dos financistas na mídia prevê a influência na estruturação de políticas e nas tomadas de posição com o intuito de garantir que interesses específicos sejam cumpridos na direção desejada, por outro lado, pode ainda haver um envolvimento direto a partir do financiamento de campanhas - manobra muito comum e polêmica na sociedade brasileira.

Nesse processo, o discurso sobre o 'bem comum' auxilia na cristalização de determinadas visões neutralizando as tomadas de posição e escondendo os jogos de poder ali existentes. 0 discurso proferido em nome do bem comum lança ideias a partir de outro patamar, torna-se isento dos interesses pessoais na medida em que reveste seus argumentos do critério universal - tal 
como os juristas de Estado apresentados por Bourdieu (2012). Contudo, diferente do que se apregoa, essa universalidade não é rigorosamente universal estando sob influência das relações entre grupos políticos que definem o que é o 'bem comum', das disputas em que estes estão inseridos no interior do campo político e das disputas no campo do poder.

Observa-se com isso que, nos referidos campos, os discursos do universal, do isento, do imparcial, buscam legitimar ações que não necessariamente cumprem estas lógicas. Ao contrário, interesses específicos de grupos fortalecidos são defendidos ganhando status de representativos, fator que repercute diretamente na interpretação do cenário aqui analisado e no entendimento da lógica de formação dos enquadramentos sobre a realidade social.

\section{Previsões, medições e prescrições}

Nesse contexto em que a interseção entre os campos econômico, político e midiático criam formas de interpretar a realidade brasileira no período analisado, aparece como fundamental o envolvimento de determinados atores neste processo. Think tanks e 'financistas-gurus' tornam-se, a partir do domínio da econometria, peças chave no processo em que são evidenciadas medições e apresentadas prescrições diante do que se espera para o futuro brasileiro.

Das estratégias mais utilizadas no período de constituição das campanhas eleitorais de 2002, o pânico econômico certamente foi a que mais se destacou diante da possibilidade de Lula, candidato do Partido dos Trabalhadores, chegar ao poder. Parte da elaboração desse temor, que se propagava a partir da mídia, consistia em criar situações que ligassem a imagem do candidato a situações de crise econômica já vividas pela população brasileira. Desse modo, oposições e imposições do novo sobre 
o velho, do moderno sobre o arcaico, do futuro sobre o passado, davam força à difamação daquele candidato e permitia que a agenda neoliberal ganhasse força argumentativa, mesmo que Lula dominasse a disputa política nas pesquisas de opinião (Assis, 2016).

Tal formulação sobre a possibilidade do 'caos' e sua consequente disseminação teve início nas grandes organizações de produção do conhecimento, denominadas think tanks - fortemente influenciadas pelos grandes centros de difusão das pautas e práticas neoliberais originários de países como os Estados Unidos. No Brasil, naquele momento, a Casa das Garças ${ }^{7}$ sobressai como agente produtor desse tipo de visão de mundo, composta por membros cuja atuação fora expressiva durante os anos de governo FHC, sua influência no contexto brasileiro já se fazia sentir desde a formulação do Plano Real no governo Itamar Franco (PMDB).

As proposições ali produzidas foram sendo acatadas pela mídia e divulgadas, ganhando, aos poucos, ar de naturalidade - processo que depende, em parte, de formulações acessíveis ao grande público e, portanto, dotadas de baixo teor analítico. 0 seu perfil e o das políticas que desenvolvem estão relacionados diretamente com a circulação internacional de seus membros - economistas, e seu poder de persuasão explica-se pela sobrevalorização dos economistas no Estado, resquícios das heranças de um projeto de país (Loureiro, 1997). Essa internacionalização pela qual passa os economistas permite a criação de uma pauta econômica, que reverbera nos campos político e social em conformidade com a agenda internacional dominante - neste momento aquela que privilegia o mercado financeiro.

7 A Casa das Garças embora formalizada em 2003 já atuava como grupo no que se refere aos participantes e membros, por isso adotou-se aqui o seu nome como denominador deste grupo de economistas, a serem descritos posteriormente, mesmo no período anterior à sua institucionalização. 
Segundo Dixon (2008), a história do neoliberalismo é também a dos think tanks, de modo geral, retrata os esforços para fazer provar e disseminar uma nova visão concorrente à keynesiana. Em âmbito nacional, as influências da agenda criada pelos thinks tanks internacionais partidários do neoliberalismo também se fizeram sentir. 0 processo de globalização, as pressões de instituições, tais como FMI e Banco Mundial, as crises internacionais, o colapso do socialismo e o fim da Guerra Fria ditaram o curso das mudanças ocorridas, mas não mais do que as escolhas dos agentes que compunham as elites dirigentes (Diniz, 2005).

Após a reconstrução do regime democrático concretizado com a Constituição de 1988 são adotadas reformas orientadas ao mercado, as quais se caracterizam pelas privatizações, abertura externa e a reorientação das políticas públicas, ganhando espaço as políticas monetaristas que visam o equilíbrio macroeconômico. Ganham espaço os ideais liberais em difusão no mundo e encontram espaço nas políticas de governo de Collor, governo a partir do qual se tem início a guinada liberal legitimada pela crítica aos marajás e pelo peso do atraso atribuído ao Estado entram em ação as formulações favoráveis à desregulamentação da Economia, à abertura comercial, às privatizações e ao projeto de Estado mínimo. Considerados policy makers - tomadores de decisões políticas sem serem considerados políticos de fato, tornam-se definidores de cenários com grande poder de estruturação das pautas, garantindo seu traço autoritário e arrogância técnica (Balieiro, 2008).

Assim, em meados da década de 1990, o que já vinha sendo sinalizado desde a eleição de Collor, tem continuidade com Fernando Henrique Cardoso. Este, propõe um pacote de reformas orientadas ao mercado e reformas constitucionais, que alteram o padrão de desenvolvimento com relação ao anterior, tendo em vista o 'desmonte da Era Vargas' - desestrutura-se o equilíbrio entre empresas estatais, nacionais e estrangeiras dando maior peso às últimas, resultando no enfraquecimento do pacto en- 
tre Estado e burguesia nacional uma vez alterada a política de industrialização por substituição das importações (Diniz, 2005; Bresser-Pereira, 2000; 2006).

No entanto, embora mudanças significativas tenham ocorrido, não houve, segundo Couto e Abrucio (2003), durante os oito anos de Governo FHC uma definição precisa sobre o novo modelo de Estado pretendido - o Plano Real iniciado no governo Itamar Franco, no qual Fernando Henrique Cardoso fora Ministro da Fazenda, trouxe os argumentos para 'um novo Brasil', mas o grupo não se preocupou em defini-lo estritamente. 0 que, em certa medida, justificaria o empenho em desqualificar a visão de mundo oposta ao projeto em curso.

A hegemonia da $\mathrm{PUC}^{8}$ (Pontifícia Universidade Católica) no governo FHC permite compreender o quão tendenciosas podem ser as tomadas de posição na medida em que estes 'policy makers' pertencem à mesma corrente de pensamento e partem, portanto, para as decisões tendo em vista interesses dos grupos os quais defendem ${ }^{9}$. Praticamente todos passaram pela mesma Universidade. Com exceção de Francisco Lopes formado na UFRJ, mas, que, no entanto, cursara o mestrado na FGV-Rio, foram treze economistas da PUC a passar pelo governo: Winston Fritsch, Edmar Bacha, André Lara Resende, Persio Arida, Pedro Malan, Gustavo Franco, Armínio Fraga, Beny Parnes, José Guilherme Reis, Demósthenes Madureira de Pinho Neto, Edward Amadeo Francisco Lopes e Ilan Goldfajn.

8 A PUC, sobretudo a PUC-Rio, teve destaque juntamente com a Fundação Getúlio Vargas (FGV) no processo de internacionalização da produção acadêmica em Economia a partir da década de 1970. Em decorrência desse movimento tornou-se uma das escolas mais representativas da vertente liberal, principalmente pela atuação de professores americanos em cursos de pós-graduação e do envio de professores e doutorandos para os Estados Unidos (Loureiro, 1997; Cantu, 2009; Assis, 2016).

9 Como ressaltam Sallum (2000), Balieiro Júnior (2008) e Loureiro (1997), o fato desses economistas em suas trajetórias tornarem-se professores do Departamento de Economia da PUC explica o perfil mais ou menos semelhante entre eles com uma forte unidade e identidade cultural. 
De acordo com Dixon (2008), os think tanks podem ser entendidos como organizações que se apresentam voluntariamente nos debates e fóruns de reflexão, mas, que, no entanto, procuram tornar-se vetores privilegiados do ativismo político de determinados intelectuais - se tornando um importante instrumento para influenciar os domínios políticos e econômicos. No esforço de compreender como se dá a construção das ideias do neoliberalismo na academia, e consequentemente sua disseminação, ele busca ressaltar o papel desempenhado pelos intelectuais dispostos nestas grandes instituições de pesquisa como os think tanks.

O autor conclui que o papel do intelectual é relevante na medida em que refere-se, para além da construção de uma nova opinião, à edificação de uma forma de pensar - cenário muito mais complexo, pois depende do poder simbólico atribuído a cada um dos agentes em jogo. Depende assim da construção de um senso comum, capaz de atribuir normalidade às formas de interpretação. Por isso, como aponta Dixon, as abordagens são estruturadas a partir de dualidades que auxiliam na caracterização do ponto de vista concorrente como sendo negativo.

Essa questão faz vir à tona a estruturação da doxa, um senso comum que opera no campo e que contempla tudo o que é admitido como "sendo assim mesmo" (Thiry- Cherques, 2006, p. 37) - tudo aquilo sobre o qual os agentes estão de acordo, a exemplo dos sistemas de classificação.

Não bastasse as investidas dos think tanks para a criação de um cenário amedrontador do ponto de vista econômico, suas profecias parecem se profetizar na medida em que índices de avaliação do cenário por instituições internacionais ocupam constantemente o noticiário econômico sempre acompanhados de 'sugestões' para o encaminhamento das políticas econômicas - mesmo crises políticas são medidas em sua expressividade a partir do grau de risco econômico que oferecem. 
É exemplo a criação em 2002 do Lulômetro por um economista do banco de investimentos Goldman Sachs, Daniel Tenengauzer. Tal indicador calculava o nível a que o dólar poderia chegar caso Lula vencesse as eleições presidenciais, fazia proveito do cenário impreciso quanto aos rumos da política econômica diante da vitória de Lula, mas a isso vinculava uma atividade real, dando margem às interpretações possíveis do caos que poderia se tornar o país a partir da influência direta que este 'risco Lula' teria sobre a relação dólar-real.

Em diversas matérias o jornal 0 Globo trata da questão como algo a ser considerado, de acordo com as cotações de Lula e Serra, segundo o Lulômetro: se Lula fosse eleito o dólar poderia chegar a $\mathrm{R} \$ 3,04$ enquanto Serra estabilizaria o dólar em $\mathrm{R} \$ 2,52$. Embora o índice não tenha sido levado muito a sério, a reportagem apresenta a fala do economista Fernando Ferreira, sócio da Consultoria Global Invest, para corroborar com a ideia de que embora pareça irreal, de fato os juros sobem com as expectativas de vitória de Lula: "É grotesco e irônico, mas há uma relação entre a alta do dólar e o desempenho de Lula nas pesquisas" ${ }^{\prime 10}$.

Mesmo se tratando de uma situação hipotética opera no imaginário favoravelmente a todo o cenário de caos e instabilidade que se previa pelo grupo favorável ao candidato da situação - o temor dos investidores era algo concreto, mas ao ser divulgado ganhava dimensões extra na abordagem midiática. Fato observável em matéria do Estadão em 10 de junho de 2002: “PSDB manterá a tática de associar Lula ao caos", na qual reitera a tática do terror financeiro como parte da campanha peessedebista. Nesse mesmo dia, outros jornais como 0 Jornal da Tarde e 0 Globo reiteraram esse intento do grupo ainda no poder - são títulos das matérias respectivamente: "Medo: a aposta tucana" e "Crise beneficia Serra". 
Isso posto, permite refletir sobre a estreita relação entre produção de conhecimentos e pontos de vista pelos think tanks, a construção de métricas de avaliação de cenário - característica dos mundos econômico e financeiro -, e sua propagação pelos meios de comunicação que dão peso característico a este tipo de informação de acordo com suas inclinações. Interessante ainda pensar que esse tipo de avaliação/métrica do cenário conjurada a uma emissão de 'opinião' por determinados agentes estende-se até mesmo para situações em que a pauta não é o econômico - são usadas para medir a potencialidade de determinado fenômeno/acontecimento no contexto do país a partir do grau de risco econômico que oferecem ${ }^{11}$.

Outra investida na tentativa de performar a realidade é a participação de determinados personagens, proeminentes do mercado, em análises de conjuntura ou prescrições de conduta diante de um determinado cenário - obviamente fundamentadas em interesses específicos ligados ao favorecimento do mercado e apoiadas no poder simbólico que constituem.

O trabalho de construção da realidade social é um trabalho coletivo, mas nem todos contribuem para ele no mesmo grau. Há pessoas que têm mais peso que outras nas lutas simbólicas pelo poder de se construir a realidade social (Bourdieu, 2014). Assim, os indivíduos, agentes neste caso, se expressam a partir de diferentes graus de autoridade, cujo peso de suas palavras está associado a seus capitais, à forma como são formuladas e às cir-

11 Os resultados das eleições são discutidos à luz de sua influência nas projeções de desempenho econômico futuro. Ver: Para ministro, Lula é o que gera instabilidade. Folha Online, 08 jun. 2002. Brasil. Disponível em: <http://www1.folha.uol.com.br/fsp/brasil/ fc0806200208.htm>. Acesso em 29 abr. 2017; Ver: Soros diz que EUA irão impor Serra e que Lula seria o caos. Folha Online, 08 jun. 2002. Brasil. Disponível em: < http://www1. folha.uol.com.br/fsp/brasil/fc0806200202.htm>. Acesso em: 30 abr. 2017; Lula diz que governo devia ter mandado Soros calar a boca. Estadão Online, 11 jun. 2002. Política. Disponível em: <http://politica.estadao.com.br/noticias/geral,lula-diz-que-governo-devia-ter-mandado-soros-calar-a-boca,20020611p56477>. Acesso em: 01 mai. 2017. 
cunstâncias em que são ditas (Thompson, 2014), considerando-se a fala dos agentes como instrumento de coerção e de imposição de visões econômicas e políticas, a qual por sua vez não está dissociada do plano social, se legitimando e difundindo por meio de disputas simbólicas.

A julgar pela significância que o período demonstrava em torno de possíveis alterações no plano político econômico brasileiro diante da possibilidade de vitória de Lula, atores e ideias vêm a público em defesa do seu ponto de vista - estes demarcam a defesa dos signos vigentes trilhados fortemente desde os anos 1990. Exemplar nesse sentido é a figura de George Soros, que diante de sua posição no mercado internacional, teve suas impressões sobre a possível vitória de Lula inúmeras vezes replicadas pela mídia: "Brasil ruma para a falência depois da eleição, diz

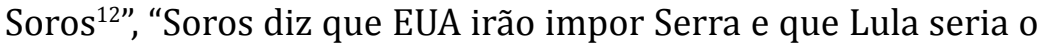
$\operatorname{caos}^{13 ", ~ " G e o r g e ~ S o r o s ~ d i z ~ q u e, ~ s e m ~ a j u d a, ~ B r a s i l ~ p o d e ~ q u e b r a r ~}{ }^{14 "}$. $\mathrm{Na}$ lista da Forbes como uma das pessoas mais ricas do mundo, ficou conhecido por suas investidas no ramo da especulação e atualmente usa de seu capital econômico para influenciar na política a partir do financiamento de campanhas. No Brasil, possui fortes vínculos com Armínio Fraga, ex-Ministro da Fazenda de FHC. Recentemente mudara sua roupagem de um investidor agressivo para um filantropo e filósofo social apoiando inclusive candidatos democratas nos Estados Unidos. Soros é exemplo de como o capital simbólico atua na justificação de sua posição naturalizando o seu ponto de vista e consequentemente o isen-

12 Ver: Brasil ruma para a falência depois da eleição, diz Soros. Folha Online, São Paulo. 30 set. 2002. Mercado. Disponível em: < http://www1.folha.uol.com.br/folha/dinheiro/ ult91u56339.shtml>. Acesso em: 30 abr. 2017.

13 Ver: George Soros diz que, sem ajuda, Brasil pode quebrar. BBC Brasil, 27 jun. 2002. Economia. Disponível em: <http://www.bbc.com/portuguese/economia/020627_sorosdb1.shtml>. Acesso em: 30 abr. 2017.

14 Ver: Soros diz que EUA irão impor Serra e que Lula seria o caos. Folha Online, 08 jun. 2002. Brasil. Disponível em: < http://www1.folha.uol.com.br/fsp/brasil/fc0806200202. htm>. Acesso em: 30 abr. 2017. 
tando de julgamentos. É esse capital, traduzido em poder simbólico, que permite que opiniões ganhem teor de 'verdades' e que o jogo político e econômico possa ser controlado por atores específicos (Bourdieu, 2012).

Nessa batalha as agências de classificação de risco também são importantes, assim como os bancos de investimento. Exemplo significativo ocorreu durante as guinadas de Lula nas sondagens de opinião sobre as eleições presidenciais em abril de 2002, os bancos Morgan Stanley e Merryl Lynch rebaixaram a recomendação de compra de títulos brasileiros através da publicação de um relatório no qual atribuía nominalmente a Lula o rebaixamento da credibilidade do país, juntamente com o aumento do índice do risco Brasil que, de um dia para o outro, subiu de 815 para 825. Como consequência, os C-Bonds (título da dívida brasileira muito negociado no mercado internacional) tiveram uma queda expressiva ${ }^{15}$. A situação é ratificada pelo uso recorrente de gráficos, muito frequentemente usados pela mídia, mas com pouquíssimas explicações, como é o caso das matérias sobre a influência das eleições no mercado financeiro em que são apresentadas projeções que mostram a queda expressiva, em pontos percentuais, na Bolsa de Valores de São Paulo, o aumento significativo dos juros e também do dólar de acordo com o aumento da porcentagem de intenções de voto para Lula ${ }^{16}$.

Importante fator para a legitimação desse perfil de informação é a Econometria, que embora tenha sido um recurso utilizado primeiramente pelo setor financeiro e empresarial, também passou a ser incorporada pelo Estado. Sua importância reside na atribui-

15 Ver: Rumor sobre pesquisa eleva o dólar em 1\%. Folha Online, São Paulo, 16 abr. 2002. Mercado. Disponível em: < http://www1.folha.uol.com.br/fsp/dinheiro/fi1604200233. htm>. Acesso em: 01 mai. 2017.

16 Ver: Dólar cai a R\$3,169 com rumores sobre pesquisas eleitorais. Folha Online, São Paulo, 16 ago. 2002. Mercado. Disponível em: <http://www1.folha.uol.com.br/folha/dinheiro/ult91u53701.shtml>. Acesso em: 01 mai. 2017; 0 nervosismo do mercado mostra sua cara. 0 Globo, versão impressa, Rio de Janeiro, p.4. 13 jun. 2002. Brasil. 
ção de neutralidade política e ideológica nos modelos lançados, embora não esteja livre da manipulação de dados, dos números. Porém, o uso da estatística e a aplicação de modelos matemáticos permitem que a crença sobre sua neutralidade reverbere e se legitime. Com o uso de cálculo e estatística deixa de ser dedutiva para se tornar prescritiva, não exigindo suporte de nenhuma autoridade na medida em que o cálculo é demonstrável (Lebaron, 2000).

Tornou-se fundamental diante dos avanços tecnológicos e as necessidades do sistema econômico perante a matematização da atividade econômica. Essa aliança entre sistema matemático, a estatística e o desenvolvimento de tecnologias para a área, garante a imersão cada vez maior dos agentes no complexo universo da atividade econômica (Callon, 1998).

Atrelada ao economês compreendido apenas pelos iniciados, garante através dos usos de termos como swap, captação, câmbio, superávit primário, risco país, déficit fiscal, o domínio do debate. Ortiz (2006) afirma que a linguagem utilizada e disseminada pela mídia funciona como dominação social do grupo que possui conhecimento sobre o assunto. Esse fator contribui, como ressalta Puliti (2009), para a legitimação dos economistas e financistas na interpretação dos cenários.

Nesse processo de legitimação a mídia torna-se fundamental na produção de consensos uma vez que elabora pautas e pressiona a adoção de determinada política. Ao final, o objetivo é influenciar as esferas de poder rumo a um caminho pré-determinado. Desse modo, o espaço atribuído às falas, sua duração e a importância que lhe são atribuídas traz, não apenas, indícios do grau de força que este tipo de 'entendimento' da realidade brasileira possui perante os demais, como também permite compreender os interesses que constituem a ação midiática.

É evidenciada, a partir desta análise, a importância em ultrapassar a lógica objetiva das previsões e prescrições na com- 
preensão dos mundos econômico, político e social. Mostra-se relevante um olhar desmistificador capaz de elucidar complexidades inerentes a contextos nos quais dispositivos e conceituações econômicas apareçam como condutores de interpretações sobre a realidade. Nesse aspecto, a Sociologia Econômica se revela essencial.

\section{Concretizando olhares, produzindo caminhos}

Dito isso, é possível salientar que a disputa eleitoral diz respeito, mais amplamente, a atribuições diferentes sobre a ordenação da sociedade brasileira e encontra-se alicerçada sobre duas propostas distintas de como deveria se dar a relação do Estado com a economia. Por isso, torna-se interessante a observação de como os conflitos se desdobram e os dispositivos que são utilizados para legitimar e estabelecer uma concepção de 'futuro' para o país naquele dado momento.

Muito do que ali se expressa advém da forma como o pensamento neoliberal se edificou no país na década de 1980 se apresentando como estratégia inovadora para o enfrentamento de desafios trazidos pela recessão do final da década de 1970 (Diniz e Boschi, 2000) - através da reestruturação econômica -, a promessa de solucionar os males provocados pelo atraso permite o surgimento de pautas como desestatização, abertura econômica e a desregulamentação financeira, fundamentais para a agenda de reforma do Estado que se estrutura. Impulsionar a dinâmica social rumo a esta nova forma propicia a propagação de pontos de vista de determinados grupos e atores, engendrados por elites intelectuais favoráveis a este percurso a partir de um movimento global (Diniz, 1993; Dixon, 2008).

Nesse período, o papel dos intelectuais, sobretudo dos economistas, é fundamental para se constituir uma nova prática política, tal como os Chicago Boys no Chile, no Brasil estes são prepon- 
derantes para as transformações ocorridas no contexto político e econômico, ganhando espaço de atuação no Estado (Loureiro, 1997; Cantu, 2009). Desse modo, é válido inferir que as disputas no interior do campo dos economistas também repercutem no plano político.

Em paralelo à expansão da atuação dos economistas, que contribui para consolidação desse novo olhar, há também o trabalho de reconstrução do senso comum por meio da desqualificação de adversários, mais precisamente, nesse momento, dos adeptos ao Keynesianismo sempre tachados como arcaicos, utópicos e corporativistas (Dixon, 2008), situação que torna relevante a lógica perpetrada pelo discurso e a compreensão do sucesso de alguns deles, bem como a identificação do espaço onde são construídos e veiculados tais discursos e quem os compartilha.

Parte desse êxito se explica pela fácil apropriação do discurso econômico por atores políticos e sua capacidade de impô-lo no espaço público. Nesse processo é fundamental a assimilação por parte do grande público - dificilmente conceitos escolásticos chamariam a atenção em um debate sobre o aumento da taxa de juros, por exemplo -; sua aceitação requer, desta maneira, uma estrutura que, revestida do poder simbólico do conhecimento científico, seja apresentada a partir de referências, não só do cotidiano, mas que tenham diálogo com as chaves cognitivas aceitas pelo senso comum. Passam a ser fundamentais as metáforas, cuja representação legitima uma lógica de pensar para além de sua afirmação, e o discurso midiático aproximando o debate das estruturas de enquadramento das opiniões populares. É a partir dessas estruturas que torna possível a reverberação no campo social de lógicas e modelos concebidos a partir das proposições dos campos político e econômico (Assis, 2016).

Parte dessa repercussão pode ser atribuída à doxa, cuja conceituação a coloca como próxima a juízos de valor elaborados por determinados agentes e que embora faça uso do status científico, 
não atinge o grau de conhecimento puro, verdadeiro, como requer os preceitos filosóficos. Ela aparece aqui circunstanciada na forma de opiniões e análises corriqueiras feitas por intelectuais com presença assídua nos debates midiáticos e tem como consequência a delimitação de uma fronteira entre aqueles que seguem os cânones do conhecimento científico e aqueles cujas representações não mais se estabelecem a partir do padrão intelectual erudito. Em decorrência disso, a visibilidade na mídia se torna uma nova instância de consagração e legitimação dos ditos pseudointelectuais. 0 reconhecimento e exposição midiáticos deixam, aqui nesse caso, em segundo plano o julgamento pelos pares.

Uma vez que a mídia se apresenta como espaço de consagração ela se torna responsável pela heteronomia no campo dos intelectuais, em que novas regras e condutas são estabelecidas e disputam com outras já consolidadas, ela passa a ter papel de destaque atuando como canal de difusão de ideias e pontos de vista - há também uma velocidade diferente na produção dos textos de alta circulação e nas referências aos resultados e na forma como o levantamento de dados e pesquisas são feitos. Ali, o foco também muda e, para além da relação economia e mídia, pode-se citar a relação economia e produção de conhecimento em que o interesse reside muito mais nas altas taxas de publicação e de venda. Com isso são enfatizados pensamentos prontos e de rápida assimilação, na maioria das vezes 'respeitando' os pontos de vista legítimos culturalmente (Pinto, 2009). Desse modo, como bem salienta o autor, a doxa ganha legitimidade no espaço de produção de visões de mundo, apresentando valores que são compartilhados por universos pouco autônomos como a grande mídia e a política.

Para que a doxa cumpra seu papel é necessário que os interlocutores sejam rápidos e performáticos, pois são na maioria das vezes instigados a realizar análises de conjuntura momentâneas que, por isto, se baseiam em dados superficiais que dificilmente produzem análises que fogem dos enquadramentos dominados pelo público-alvo - situação atípica da realidade do intelectual 
stricto sensu. Assim, a habilidade dos interlocutores se prova pela capacidade de produzir discursos que tenham roupagem científica, mas que no fundo favorecem interpretações e visões de mundo específicas através da combinação de linguagens de domínio científico e termos próximos àqueles do cotidiano, o que lhes permitem ao mesmo tempo ser 'compreensível a todos os ouvidos' e se livrar de questionamentos e reflexões que de imediato visem por em xeque a superioridade de tal posicionamento. Esse processo atribui ao economicismo caráter de ordem natural tendo como característica o incontestável, se apresentando como metadiscurso do consenso (Guilbert, 2014).

Vale ainda lembrar que, nessa perspectiva, o processo de produção dos pontos de vista depende do desenvolvimento de duas circunstâncias distintas: aquela em que são produzidas as teorias e os conceitos capazes de demonstrar e provar seu ponto de vista por meio de pesquisas e análises as quais se sustentam por atividades e produções intelectuais relevantes, e aquelas em que ocorre a apropriação destes conceitos, sobretudo os que estão em conformidade com a ordem vigente por aqueles cujo intuito é a difusão rasa de idealizações através da mídia.

Em meio a esse processo, os think tanks são fundamentais para a disseminação de lógicas que são exploradas a partir de alguns conceitos teóricos e apresentadas sem o máximo rigor analítico nas emissões jornalísticas, inicia-se então o que Halimi (2005; 2012) considera o processo de vulgarização da análise. No contexto aqui desvelado, os think tanks, em sua grande maioria, pertenciam a escolas favoráveis ao mercado sendo defensores da continuidade do caminho traçado por Fernando Henrique Cardoso, muitos com o histórico de participação no Plano Real ${ }^{17}$.

17 A maneira como a participação no Plano Real é tratada nas apresentações dos economistas traz o tom para o que se objetiva como resultado. Em meio as previsões de caos diante da possibilidade de vitória de Lula, as análises daqueles que participaram de um processo vitorioso confrontam diretamente a possibilidade do caos com a concretude da solução, do sucesso. 
Seu grau de força na mídia é notório principalmente em comparação aos defensores da visão concorrente, a forma como suas imagens são apresentadas, suas falas corroboradas e a visibilidade das notícias ou pautas em que aparecem também chamam atenção pela diferenciação no tratamento ${ }^{18}$. As credenciais de passagem pelo mercado financeiro também são sempre utilizadas como indícios da técnica, do conhecimento formal aliado ao conhecimento prático, este processo em muito se relaciona com aquele de estruturação e disseminação da doxa. Nele se concentram atitudes para a estruturação de conceitos, expressões e noções partilhadas que limitam o pensável e que contam com o poder de divulgação midiático, reiterando sempre a sua ligação com um fato bem-sucedido no passado, oferecendo comparações e alimentando o imaginário social.

O debate que se apresenta naquele momento mostra-se muito mais que uma luta política, se refere à uma luta cognitiva na qual estava em jogo não apenas questões partidárias ou a falta de jeito de Lula com o mercado financeiro, mas, sim, a estrutura de poder a ser prevalecente na sociedade a partir dali. As propostas apresentadas pelo governo Lula representavam, ao menos num primeiro momento, a alteração do modus operandi econômico e por conseguinte do enquadramento cognitivo dado que outros parâmetros estavam sendo propostos para a definição da conduta do Estado brasileiro (Assis, 2016).

Nota-se diante do percurso analisado que a disputa esteve a todo momento subordinada a uma agenda construída após o processo de redemocratização e em consonância com a agenda internacional, concretizada ao longo dos oito anos do governo de Fernando Henrique Cardoso e que enfrenta naquele momento o risco de ter seu curso alterado. 
Por isso, nessa interseção entre os interesses econômicos, a cena política e o poder midiático, dominar este embate significa direcionar e até mesmo dominar o léxico a partir do qual são expressadas as ideias de governo, trata-se de construir pautas e dominar a agenda, ou seja, conduzir enquadramentos performando a realidade. Nesse ínterim, considerando que a interpretação da realidade está sujeita às categorias que são utilizadas para julgá-la e analisá-la, alterando as categorias, consequentemente, são modificadas as concepções sobre a realidade social (Foucault, 1984; Hacking, 1983).

Nesse cenário no qual as estruturas já pareciam estabelecidas e os enquadramentos estruturados, esforços muito mais significativos seriam necessários para que enquadramentos já existentes pudessem ser ressignificados (Assis, 2016) - o que se encontra fora da política hegemônica é estigmatizado, torna-se obsoleto, fracassado, fora dos caminhos aceitáveis. Parâmetros são mobilizados para a descaracterização de Lula como presidente por seu 'despreparo' diante do cenário complexo formado por exigências do mercado e de investidores. Personagens importantes estiveram ligados à concretização do cenário favorável ao grupo ligado a FHC e às ideias por ele defendidas, mesmo depois da derrota de seu candidato nas urnas.

Seus princípios teóricos de embasamento, a partir da legitimidade adquirida em um momento crucial da cena econômica brasileira, continuaram a reverberar mesmo após a saída de Fernando Henrique Cardoso do poder e puderam conduzir os debates no espaço político durante os primeiros anos do governo Lula ${ }^{19}$. 0 domínio dos enquadramentos, dos signos, do léxico permitiu a construção de situações com «teor〉 de verdade, repercutindo no espaço social e moldando o cenário a ser enfrentado pelo então presidente.

19 Situação que se transforma e é ressignificada com o tempo, como demonstrado em: Jardim, Maria C. Entre a Solidariedade e o Risco. Sindicatos e Fundos de Pensão em tempos de governo Lula. Annablume, Fapesp, 2009. 
Todo esse movimento é ainda reforçado e normalizado através da universalidade correspondente à defesa do bem comum, que aliado à racionalidade e à objetividade encobre os interesses e dissimula as ações dos agentes envolvidos neste processo.

\section{Considerações finais}

Tendo em vista as questões que envolveram a cena contemporânea brasileira, este artigo teve por intuito chamar atenção para a complexidade da interseção entre economia, política e mídia visando desmistificar a objetividade por trás desta relação que, ao ser investigada, se mostra muito mais interessante e reveladora das disputas entre visões de mundo que coexistem no contexto brasileiro e seu caráter cultural, embates cujos resultados dependem do grau de força de atores, grupos e instituições ali inseridos.

Tal temática apresenta-se como terreno profícuo para o desenvolvimento de pesquisas que ampliem sua análise considerando conjuntamente os três campos, especialmente quando episódios recentes no cenário brasileiro expõem a multiplicidade de questões decorrentes de tal proximidade, a exemplo do atual debate sobre o combate à corrupção e a defesa dos princípios democráticos. Aqui, se optou pela análise a partir dos aportes da Sociologia Econômica trazendo ao primeiro plano o interesse em romper com a concepção utilitarista do modo de interpretar o fazer e o dizer econômicos, demonstrando que nestes perpassam muitos outros fatores do que exclusivamente aqueles que movem o modelo de «homem racional».

Assim, o artigo chama atenção para a tentativa de imposição de um modo de interpretar a sociedade brasileira, em um determinado momento, estruturado no pânico em relação ao futuro econômico do país - conjuntura esta que só faz sentido levando-se em consideração os agentes, grupos e instituições, suas posições sociais articuladas com as disposições (habitus) e as tomadas de 
posições (Bourdieu, 1992; 1983). Diz respeito, de modo mais geral, ao controle da narrativa do futuro brasileiro pautado principalmente em fatores econômicos, circunstância em que chaves cognitivas específicas são fundamentais para a compreensão da controvérsia que envolve a questão.

Faz referência, portanto, ao jogo de forças que permite que categorias cognitivas específicas sejam lançadas e consideradas no plano nacional - tão interessante quanto o próprio resultado desta disputa é a forma como o debate se estrutura e desenvolve, bem como o grau de participação dos agentes e os instrumentos dos quais fazem uso para impor categorias de pensamento que lhes favoreçam. Nessa conjuntura torna-se igualmente instigante os discursos relacionados ao ethos profissional de cada uma das áreas em questão que minimizam ou escondem tomadas de posição que favorecem a defesa de um ponto de vista ou grupo em específico.

No período de disputa eleitoral entre o possível sucessor de FHC - José Serra -, e o candidato favorito (Lula), em 2002, a abordagem econômica parece ser o principal fator de diferenciação entre os candidatos, contudo, foi possível identificar neste artigo os entremeios deste debate - construído na esfera econômica com repercussão na cena política, a partir da interferência da mídia, e tendo como principais porta-vozes, na maioria das vezes, economistas renomados de grupos e escolas mainstream cujas trajetórias passam pelo mercado. A disputa indireta que se cria entre o legado de FHC - da família intelectual que pontificava em seu governo -, e o então candidato Lula faz com que a disputa entre o 'sapo barbudo' e o 'príncipe dos sociólogos' dê as dimensões simbólicas de tal disputa, ainda que este último não disputasse mais o pleito.

Nesse ínterim, o jogo mostra-se bem mais profundo do que a disputa pelo curso político e o caminho econômico a ser trilhado (Assis, 2016), demarca sobretudo as limitações dos cená- 
rios prováveis balizando as expectativas, ao mesmo tempo que a grande mídia sustenta e reproduz os argumentos proferidos por atores e grupos considerados detentores da expertise nas temáticas em questão. A luta travada, portanto, não diz respeito somente aos campos político e econômico, ao contrário, faz referência ao campo do poder e a forma como o debate se constitui, assim, dominá-los quer dizer estruturar olhares capazes de cristalizar interpretações e significados sobre a realidade social.

Desse modo, é necessário dominar o discurso. Com isso, a participação da mídia é fundamental para a construção da opinião pública, capaz de atribuir valores aos fatos e pontos de vista (Champagne, 1990). Nesse contexto turbulento, em que as inclinações são abundantes, é propícia a tentativa de demonstrar neutralidade como nas noções de bem comum e de imparcialidade que atravessam tanto a política quanto o jornalismo e que se aliam ao discurso da racionalidade econômica.

\section{Ref erências Bibliográficas}

ASSIS, K. G. Verdades Econômicas e verdades políticas - o sistema financeiro em debate. 2016. 275 f. Tese (Doutorado em Ciência Política). Universidade Federal de São Carlos.

BALIEIRO JUNIOR, J. C. M. Política e economia no governo FHC: a questão dos economistas. Tópos, Presidente Prudente, v.2, n.1, p.185-203, 2008.

BOLTANSKI, L. La souffrance à distance. Morale humanitaire, médias et politique. Paris: Métailié, 1993.

BOURDIEU, P. Campo de poder, campo intelectual. Buenos Aires: Folios, 1983.

Éditions du Seuil, 1992.

Les règles de l'art: genèse et structure du champ littéraire. Paris: Sobre a televisão. Rio de Janeiro: Jorge Zahar Ed., 1997.

Contrafogos. Táticas para enfrentar a invasão neoliberal. Rio de Janeiro: Jorge Zahar Ed., 1998. 
Letras, 2006.

As estruturas sociais da Economia. São Paulo: Campanhia das

. Sobre o Estado. Cours au Collège de France, 1989-1992. Paris: Raisons d'agir - Seuil, 2012.

. Langage et pouvoir symbolique. Paris: Points, 2014.

BRESSER PEREIRA, L. C. A reforma gerencial da administração pública brasileira. Revista de Administração Pública: dos meios aos resultados, Oeiras, v.34, n.4, p.55-72, jul./ago. 2000.

. O novo desenvolvimentismo e a ortodoxia convencional. São Paulo em Perspectiva, São Paulo, v.20, n.3, p.5-24, jul./set. 2006.

CALLON, M. The laws of the markets. Oxford: The Sociological Review,1998.

CANTU, R. Uma abordagem das elites da burocracia econômica como espaço social. In: Sociedade e Política em Tempos de Incerteza, I Seminário Nacional Sociologia e Política, Curitiba, 2009.

CAPPELLA, J; JAMIESON, K. Spiral of Cynicism. New York: Oxford University Press, 2007.

CHAMPAGNE, P. Faire l'opinion. Le nouveau jeu politique. Paris: Les Éditions de Minuit, 1990.

La double dépendence. Quelques remarques sur les rapports entre les champs politique, économique et journalistique, Hermès, La Revue, Paris, v.3, n.17-18, p.215-29, 1995.

COUTO, C. G. e ABRUCIO, F. O segundo governo FHC: coalizões, agendas e instituições. Tempo Social, São Paulo, v. 15. n.2, nov. 2003.

DINIZ, E. Neoliberalismo e corporativismo: as duas faces do capitalismo industrial no Brasil. In: Empresários e Modernização Econômica: Brasil Anos 90. Florianópolis: Editora da UFSC, 1993.

DINIZ, E. e BOSCHI, R. Globalização e elites empresariais: padrões alternativos de relações entre os setores público e privado no Brasil. ANPOCS,Petrópolis, out. 2000.

DINIZ, E. Empresariado, Estado e Domocracia: uma avaliação dos dois primeiros anos do governo Lula. Centro de Estudios Brasileños, Universidad de Salamanca, fev. 2005.

DIXON, K. Les évangelistes du marché. Paris: Raison d'agir, 2008.

DUVAL, J. Concessions et conversions à l'économie. Actes de la Recherche en Sciences Sociales, Paris, v.131-132, mars. 2000. 
Critique de la raison journalistique. Les transformations de la presse économique en France. Paris: Seuil, 2004.

FARIA, A. M. O Jornalismo Econômico e a Cobertura sobre Privatização (1990/1991). 1994. 85 f. Tese de Mestrado - Escola de Comunicações e Artes da Universidade de São Paulo, São Paulo.

FOUCAULT, M. Microfísica do Poder. In: MACHADO, Roberto (Org.). Rio de Janeiro: Edições Graal, 4ª edição, 1984.

GRÜN, Roberto. A Evolução Recente do Espaço Financeiro no Brasil e Alguns Reflexos na Cena Política. Dados - Revista de Ciências Sociais, Rio de Janeiro, v.47, n.1, p. 45-47, 2004.

A vingança do baixo clero: o desafio ao "PiG" e o estado do conflito cultural no tratamento da crise financeira. Mana, Rio de Janeiro, v. 19, n. 2, p. 303-40, aug. 2013.

GUILBERT, T. La <<mise en évidence >> du discours économique par la presse écrite. In TEMMAR, M.; ANGERMULLER, J.; LEBARON, F. Les discours sur l'économie. Amiens: Curap-Ess Editions, 2014.

HACKING, I. Representing and Interviening. Introductory Topics in the Philosophy of Natural Science. Cambridge: Cambridge University Press, 1983.

Le Grand Bond en arrière - Comment l’ordre libéral s'est imposé au monde. Paris: Agone, 2012.

HALIMI, S. Les nouveaux chiens de garde. Paris: Raison d'agir, 2005.

HIRSH, P. M; FRIEDMAN, R. “Mãos Sujas” versus “Modelos Limpos” estará a sociologia em risco de ser seduzida pela economia? In: MARQUES, R.; PEIXOTO, J. (Org.). A nova Sociologia Econômica. Oeiras: Celta Ed., 2003. p.103-23.

JARDIM, M. C. Entre a Solidariedade e o Risco. Sindicatos e Fundos de Pensão em tempos de governo Lula. São Paulo: Annablume, Fapesp, 2009.

KOVACK, B.; ROSENSTIEL, T. Os Elementos do Jornalismo: o que os jornalistas devem saber e o público exigir. São Paulo: Geração Editorial, 2004.

LAKOFF, G; JOHNSON, M. Metaphors we live by. Chicago: University of Chicago Press, 1980.

LAKOFF, G. Moral Politics: What Conservatives Know That Liberals Don't. Chicago: University of Chicago Press, 1996.

LEBARON, F. La croyance économique. Les économistes entre science et politique. Paris: Seuil, coll. <<Liber>>, 2000. 
LOUREIRO, M. R. Os economistas no governo. Gestão econômica e democracia. Rio de Janeiro: Editora da Fundação Getúlio Vargas, 1997.

MAUGER, G. Rèperes pour résister à l'idéologie dominante. Paris: Éditions du Croquant. 2013.

ORTIZ, R. Mundialização: saberes e crenças. São Paulo: Brasiliense, 2006.

PAULANI, L. Brasil Delivery: servidão financeira e estado de emergência econômico. São Paulo: Boitempo, 2008.

PINTO, L. Le café du commerce des penseurs. A propos de la doxa intellectuelle. Paris: Éditions du Croquant, coll. « Savoir/Agir », 2009.

PORTER, T. Trust in Numbers: the pursuit of objectivity in science and publlic life. Princeton: Princeton University Press, 1995.

PORTO, M. P. Enquadramentos da Mídia e Política. XXVI Encontro Anual da Associação Nacional de Pós-Graduação e Pesquisa em Ciência Sociais - ANPOCS, Caxambu, 2002.

PULITI, P. A Financeirização do Noticiário Econômico (1989-2002). 2009. 314f. Tese (Doutorado em Ciências da Comunicação). Escola de Comunicação e Artes. Universidade de São Paulo - USP, São Paulo.

SALLUM, B. O Brasil sob Cardoso neoliberalismo e desenvolvimentismo. Tempo Social, São Paulo, v.11, n.2, p.23-47, fev. 2000.

SCHEUFELE, D. Agenda-setting, priming, and framing revisited: another look at cognitive effects of political communication. Mass Communication \& Society, v. 3 , n. 2e3, 2000.

THIRY-CHERQUES, H. R. Pierre Bourdieu: a teoria na prática. Revista de Administração Pública, Rio de Janeiro, v. 40, n. 1, p. 27-53, fev. 2006.

THOMPSON, J. B. Préface. In: BOURDIEU, Pierre. Langage et pouvoir symbolique. Paris: Points, 2014.

Recebido em 24/02/2017

Aprovado em 31/05/2017 
